\title{
Long-term cultivation of colorectal carcinoma cells with anti-cancer drugs induces drug resistance and telomere elongation: an in vitro study Noritsugu Kuranaga ${ }^{1}$, Nariyoshi Shinomiya ${ }^{* 2}$ and Hidetaka Mochizuki ${ }^{1}$
}

Address: ${ }^{1}$ Department of Surgery I, National Defense Medical College, Namiki 3-2, Tokorozawa, Saitama 359-8513, Japan and ${ }^{2}$ Department of Microbiology, National Defense Medical College, Namiki 3-2, Tokorozawa, Saitama 359-8513, Japan

E-mail: Noritsugu Kuranaga - grd1409@gr.ndmc.ac.jp; Nariyoshi Shinomiya* - shinomi@ndmc.ac.jp; Hidetaka Mochizuki - mochizuki@me.ndmc.ac.jp

*Corresponding author

This article is available from: http://www.biomedcentral.com/I47/-2407/I//0

(C) 200 I Kuranaga et al; licensee BioMed Central Ltd. Verbatim copying and redistribution of this article are permitted in any medium for any noncommercial purpose, provided this notice is preserved along with the article's original URL. For commercial use, contact info@biomedcentral.com

\begin{abstract}
Background: The role of telomerase activation in the expression and/or maintenance of drug resistance is not clearly understood. Therefore, we investigated the relationships, among the telomerase activity, telomere length and the expression of multidrug resistance genes in colorectal cancer cell lines cultivated with anti-cancer drugs.

Methods: LoVo and DLD-I cells were continuously grown in the presence of both CDDP and 5FU for up to 100 days. Cell proliferation, telomerase activity, telomere length and the expression of multidrug resistance genes were serially monitored as the PDL increased.

Results: The expression of multidrug resistance genes tended to increase as the PDL increased. However, an abnormal aneuploid clone was not detected as far as the cells were monitored by a DNA histogram analysis. Tumor cells showing resistance to anti-cancer drugs revealed a higher cell proliferation rate. The telomere length gradually increased with a progressive PDL. The telomerase activity reached a maximum level at I5 PDL in LoVo cells and at 27 PDL in DLD-I cells. An increase in the mRNA expression of the telomerase components, especially in hTERT and in hTR, was observed at the same PDLs.

Conclusions: These results suggest that a high telomerase activity and an elongation of telomeres both appear to help maintain and/or increase drug resistance in colorectal cancer cells. Cancer cells with long telomeres and a high proliferative activity may thus be able to better survive exposure to anti-cancer drugs. This is presumably due to an increased chromosome stability and a strong expression of both mdr-I and MRP genes.
\end{abstract}

\section{Background}

We often encounter patients with tumors acquiring multidrug resistance during the course of chemotherapy. An acceleration of the cancer cell proliferation is one of the most troublesome problems in actual clinical situa- tions. The multidrug resistance gene (mdr-1) and multidrug resistance-associated protein (MRP) have been studied in various human tissues [1-3], and they have been proven to play a central role in the progression of drug resistance in colorectal cancers. mdr-1 and MRP 
genes have been reported to be amplified in carcinoma cells and they also frequently exist on abnormal chromosomes such as double minute chromosomes [4-6]. However, the mechanism regarding how these genes stably exist on abnormal chromosomes of replicated tumor cells is still not sufficiently understood.

On the other hand, telomere shortening has been reported to be involved in the formation and preservation of abnormal chromosomes [7]. In addition, once tumor cells acquire telomerase activity, the telomere length has been shown to be maintained [8-11]. In such cases, abnormal chromosomes are considered to be stably passaged to the daughter carcinoma cells. Up to now, there have been numerous papers focusing on the role of telomerase activation in the progression of cancer cells, but the relationship between telomerase activation and drug resistance has not yet been clearly explained.

In this study, we investigated the long-term effects of CDDP and 5-FU, both of which are often used as anticancer drugs in the actual clinical treatment of the colorectal cancers, on two colorectal adenocarcinoma cell lines, LoVo and DLD-1. We cultivated these cells in the presence of CDDP and 5-FU for more than 100 days, and thus obtained cancer cells that were both highly resistant to anti-cancer drugs and grew rapidly. By using these multi-drug resistant cells, we investigated the relationship among the proliferative activity, drug resistance and telomerase-related components, including the telomere length, telomerase activity and telomerase genes.

\section{Materials and methods \\ Cell lines and culture conditions}

The established human colon adenocarcinoma cell lines, LoVo (JCRB9083) and DLD-1 (JCRB9094), were purchased from Health Science Research Resources Bank. Cells were grown in RPMI1640 medium (Iwaki, Tokyo) containing 10\% heat-inactivated fetal bovine serum ( $\mathrm{Hy}-$ Clone $\left.{ }^{\circledR}\right)$ and anti-cancer drugs indicated as below. Falcon 3002 culture dishes were used for all cell passages. Cell passages were performed when the cells reached confluence.

\section{Anti-cancer drugs}

cis-diamminedichloroplatinum (CDDP), the DNA-intrastrand cross-linker, which inhibits the elongation of the DNA chain, and 5-fluorouracil (5-FU), one of the fluorinated pyrimidine derivatives, which inhibit thymidine synthase and form abnormal RNA were used in this study. Stock solutions of $50 \mu \mathrm{g} / \mathrm{ml}$ of CDDP (Wako Pure Chemical Co., Tokyo) and $1 \times 10^{-5} \mathrm{M}$ of 5-FU (Wako) were prepared and kept at $4^{\circ} \mathrm{C}$ in the dark. These drugs were added to the culture medium at a final concentration of $0.5 \mu / \mathrm{ml}$ of CDDP and $1 \times 10^{-7} \mathrm{M}$ of 5 -FU and then were used for the passage. The concentration of these drugs used in this study was the minimal dose that completely inhibits the growth of any non-resistant colorectal carcinoma cells (preliminary estimated). Thereafter, carcinoma cells were continuously grown in culture medium containing these anti-cancer drugs to acquire drug resistance. The dose indicated above was sufficient to both induce the drug resistance and to select drug-resistant cells. Anti-cancer drugs were renewed (added to the new culture medium) at every cell passage.

\section{Definition of the population doubling level (PDL)}

After the cultured-cells reached confluence, cells were disaggregated by trypsinization, three-fold diluted with culture media containing anti-cancer drugs, and then replated to a new culture dish. Since one PDL means doubling the number of the cells as a group, the relationship between PDL and dilution factor is defined as follows:

$2^{\mathrm{n}}=$ dilution factor $($ where $\mathrm{n}=\mathrm{PDL})$

If the logarithm of both sides is taken:

$\log 2^{\mathrm{n}}=\log$ (dilution factor)

Rearranging:

$\mathrm{n}(\mathrm{PDL})=\log ($ dilution factor $) / \log 2=\log ($ dilution factor)/0.301

Since the dilution factor in this study is 3 (three-fold dilution), the increase in the PDL per passage is calculated as $\log 3 / 0.301=0.477 / 0.301=$ ca. 1.58

\section{Flow cytometric analysis of the DNA histogram}

Carcinoma cells at each passage stage were stored at $80^{\circ} \mathrm{C}$ until the DNA histogram analysis. After all the cells were thawed at the same time, they were used for the DNA histogram analysis. All cells were processed by the detergent-trypsin method according to the manufacturer's instructions (DNA reagent kit: CycleTEST, Becton Dickinson). Briefly, $180 \mu \mathrm{l}$ of $0.003 \%$ trypsin in detergent stock solution was added to the cell suspension (ca. $1 \times 10^{6}$ cells) and mixed gently. After $10 \mathrm{~min}$ of incubation at room temperature, $150 \mu \mathrm{l}$ of the next solution (0.5 $\mathrm{mg} / \mathrm{ml}$ trypsin inhibitor $+0.1 \mathrm{mg} / \mathrm{ml}$ RNase A) was added. The solutions were mixed, and after $10 \mathrm{~min}$ at room temperature $150 \mu \mathrm{l}$ of an ice-cold solution of $500 \mu \mathrm{g} / \mathrm{ml}$ propidium iodide (PI) was added. At 15 min after the addition of PI solution fluorescence signals were measured with a FACSCalibur flow cytometer (Becton Dickinson) using a $488 \mathrm{~nm}$ argon ion laser. To ascertain the clonality change of the passaged cells, the fluorescence intensity of the DNA histogram was analyzed using the CELLQuest software package. 


\section{Cell proliferation assay}

The cells were plated at 5,00o cells per well in 96-well culture plates. The cells were grown in the presence of CDDP and 5-FU and each assay was performed in triplicate. The plates were incubated at $37^{\circ} \mathrm{C}$ for 4 days, and then the cell growth was measured using the Alamar blue assay kit as previously described $[12,13]$. Briefly, $0.4 \mathrm{ml}$ of Alamar blue solution (Wako) was diluted to $10 \mathrm{ml}$ with phosphate buffer and mixed well. Ten $\mu$ l of diluted Alamar blue was added to each well and incubated at $37^{\circ} \mathrm{C}$. After $4 \mathrm{~h}$, fluorescence at $590 \mathrm{~nm}$ (emission wavelength) was monitored with $560 \mathrm{~nm}$ excitation, and the results were expressed as the relative intensity.

\section{Telomere length}

The telomere length was determined based on the telomere restriction fragment (TRF) - Southern blot analysis as previously described $[14,15]$. The cells were digested with $400 \mu$ l of DNA extraction buffer (0.25\% $\mathrm{NP}-40,10 \mu \mathrm{g} / \mathrm{ml}$ RNase I-A, $1 \mathrm{mM}$ EDTA.2Na, $5 \mathrm{mM}$ Tris bolic acid [pH 8.o]) and proteinase $\mathrm{K}(1 \mathrm{mg} / \mathrm{ml})$. After extraction using phenol/chloroform, DNA was precipitated with ethanol and then was dissolved in distilled water. The DNA concentration was measured, and $5 \mu \mathrm{g}$ of extracted DNA was digested with 10 units of HinfI (Wako) for $1 \mathrm{~h}$ at $37^{\circ} \mathrm{C}$. Electrophoresis of digested genomic DNA was performed in $1 \%$ agarose gel in $1 \times \mathrm{TAE}$ buffer for $75 \mathrm{~min}$ at $50 \mathrm{~V}$. After electrophoresis, the separated DNA was denatured in $0.5 \mathrm{M} \mathrm{NaOH} / 1.5 \mathrm{M} \mathrm{NaCl}$ at room temperature for $15 \mathrm{~min}$, neutralized twice in $1 \mathrm{M}$ Tris/1.5 M NaCl ( $\mathrm{pH} \mathrm{7.5)} \mathrm{at} \mathrm{room} \mathrm{temperature} \mathrm{for} 5 \mathrm{~min}$, and transferred to a nylon membrane (Immobilon S; Millipore, Tokyo) using $10 \times$ SSC by a semidry electroblotter (Horizeblot, AE-6675: P/N type; ATTO, Tokyo) for $1 \mathrm{~h}$. After prehybridization in hybridization buffer $(1 \times$ SSC, 1\% milk blocking solution, 0.5\% SDS solution) at $42^{\circ} \mathrm{C}$ for $1 \mathrm{~h}$, the membrane was hybridized to a $5^{\prime}$-DIG end-labeled telomeric probe (TTAGGG) ${ }_{4}$ in hybridization buffer at $42^{\circ} \mathrm{C}$ for $16 \mathrm{~h}$. The membrane was washed in $1 \times \mathrm{SSC} / 0.1 \% \mathrm{SDS}$ solution and $0.1 \times \mathrm{SSC} / 0.1 \% \mathrm{SDS}$ solution. Telomeric smears were detected by the DIG Luminescent Detection Kit (Boehringer Mannheim, Tokyo) according to the instruction manual. After color development, the membrane image was photographed, and the peak and mean TRF lengths were analyzed on a Macintosh computer using NIH image software (version 1.60).

\section{Telomerase activity}

The telomerase activity was determined using a modified-TRAP assay [16]. This assay was performed essentially as described by Kim et al. [17] with only minor modifications. The cells were pelleted and incubated on ice for $30 \mathrm{~min}$ in $200 \mu \mathrm{l}$ of ice-cold lysis buffer $(0.5 \%$ CHAPS). The lysates were centrifuged at $16,000 \mathrm{~g}$ for 20 min at $4^{\circ} \mathrm{C}$, and the supernatant was rapidly frozen and stored at $-80^{\circ} \mathrm{C}$. The protein concentration was measured against bovine serum albumin using a Bio-Rad protein assay reagent, and an aliquot containing $0.05 \mu \mathrm{g}$ of protein was used. Assay tubes were prepared by sequestering $0.1 \mu \mathrm{g}$ of $5^{\prime}$-DIG end-labeled CX primer ( 5 -CCCTTACCCTTACCCTTACCСТАA-3') under a wax barrier (Ampliwax; Perkin Elmer Cetus, Foster City, CA, USA). Each extract was assayed in $50 \mu$ of reaction mixture containing $20 \mathrm{mM}$ Tris- $\mathrm{HCl}$ (pH 8.3), $1.5 \mathrm{mM} \mathrm{MgCl}_{2}, 63$ $\mathrm{mM} \mathrm{KCl,} \mathrm{0.05 \%} \mathrm{Tween} \mathrm{20,} 1$ mM EGTA, $50 \mu \mathrm{M}$ dNTPs, $0.1 \mu \mathrm{g}$ of $5^{\prime}$-DIG end-labeled TS oligonucleotide ( $5^{\prime}-$ AATCCGTCGAGCAGAGTT-3') and 2 units of Taq DNA polymerase (Boehringer Mannheim). After a 10-min incubation at $23^{\circ} \mathrm{C}$ for telomerase-mediated extension of the TS primer, the reaction mixture was heated and then subjected to $31 \mathrm{PCR}$ cycles at $94^{\circ} \mathrm{C}$ for $30 \mathrm{~s}, 50^{\circ} \mathrm{C}$ for 30 $\mathrm{s}$, and $72^{\circ} \mathrm{C}$ for $90 \mathrm{~s}$. The PCR product was electrophoresed on a $12.5 \%$ polyacrylamide gel and transferred to a nylon membrane by a semidry electroblotter. TRAP products were detected by the DIG Luminescent Detection Kit (Boehringer Mannheim) according to the manufacturer's instructions. After color development, the membrane image was photographed and analyzed on a Macintosh computer using NIH image software. Telomerase activity was evaluated by TRAP products/internal telomerase assay standard (ITAS) ratio.

\section{RNA extraction and quantitative reverse transcriptase polymerase chain reaction (RT-PCR)}

The total RNA from cells was obtained using ISOGEN (Wako), for semi-quantitative RT-PCR of drug resistance genes (mdr-1, MRP) and telomerase component genes (hTERT, hTR and TEP-1) according to a previously described method $[18,19]$. RT-PCR was performed with total RNA (1 $\mu \mathrm{g})$ using RNA PCR Kit (AMV) ver.2.1 (Takara, Shiga, Japan). The primers were: mdr-1, 5'primer nucleotide (nt) AAGCTTAGTACCAAAGAGGCTCTG, 3'-primer nt GGCTAGAAACAATAGTGAAAACAA; MRP, 5'-primer nt TGACATTTACCTCTTCGATGAT, 3'-primer nt GTTGTGGTGCCTGCTGATGT; hTERT, 5'-primer nt ACTTCCCTGTAGAAGACGAG, 3'-primer nt CAGAAACAGGCTGTGACACT; hTR, 5'-primer nt TCCCTTTATAAGCCGACTCG, 3'-primer nt GCTCTAGAATGAACGGTGGA; TEP-1, 5'-primer nt ATGCCAGCATGGATAGTGAG, 3'-primer nt AGGCTTTGCAT CTCTAGCAC; G3PDH, 5'-primer nt TGAAGGTCGGAGTCAACGGATTTGGT, 3'-primer nt CATGTGGGCCATGAGGTCCACCAC. The thermal cycles were: $94^{\circ} \mathrm{C}$ for $1 \mathrm{~min}, 57^{\circ} \mathrm{C}$ for $1 \mathrm{~min}\left(59^{\circ} \mathrm{C}\right.$ for hTERT) and $72^{\circ} \mathrm{C}$ for $2 \mathrm{~min}$ for 28 cycles for mdr-1, MRP and G3PDH, and 30 cycles for hTERT, hTR and TEP-1. Five $\mu l$ of each PCR product was separated on a $2 \%$ agarose gel. The gels were dyed with ethidium bromide and exposed to films under UV light and the density of each 
band was quantitated on a Macintosh computer using an NIH image software package. The level of expression of mRNA was evaluated by each gene mRNA/G3PDH gene mRNA ratio.

\section{Statistical analysis}

Differences in the means of the continuous variables between the two groups were tested by Student's $t$-test on a cell proliferation assay (Fig. 2). A $p$ value of less than 0.05 was considered to be statistically significant.

\section{Results}

Effect of long-term cultivation with anti-cancer drugs on the proliferative activity

LoVo and DLD-1 cells were continuously cultivated in the presence of anti-cancer drugs $(0.5 \mu \mathrm{g} / \mathrm{ml}$ of CDDP and $1 \times 10^{-7} \mathrm{M}$ of 5 -FU) up to 100 days, and the cell growth was monitored. Cell proliferative activity was evaluated based on the relationship between the number of cultivated days and the population doubling level (PDL) (Fig. 1). In LoVo cells, cell growth was almost completely suppressed until Day 14 . First cells gradually began to proliferate (4 PDL), thereafter the growth speed gradually increased (15 PDL) until it reached almost the same level as that of normal control cells on Day 98 (39 PDL). Similarly, DLD-1 cells could not grow during the first week in the presence of anti-cancer drugs. Although the growth speed did not reach exactly the same level as the control cells during the observation period, it reached a level very close to that of the control cells on Day 85 (58 PDL).

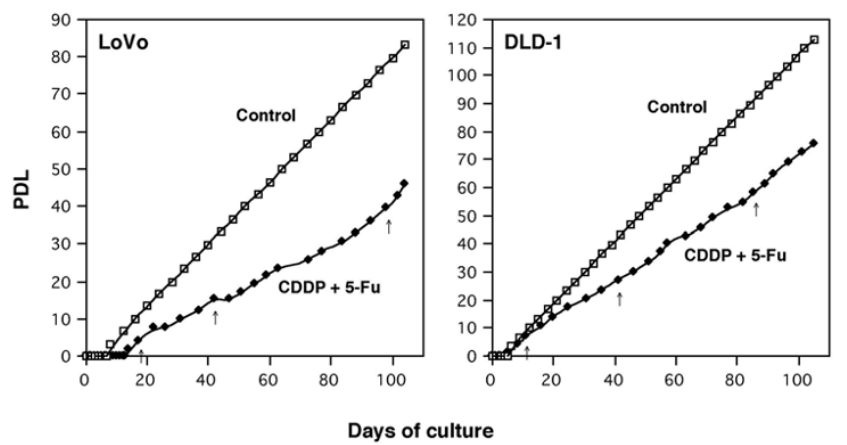

Figure I

Relationship between culture days and population doubling level (PDL). Colon adenocarcinoma cells (LoVo and DLD-I) were continuously passaged in the culture medium containing $0.5 \mu \mathrm{g} / \mathrm{ml}$ of CDDP and $\mathrm{I} \times 10^{-7} \mathrm{M}$ of $5-\mathrm{FU}$. (Clear square): control cells (without anti-cancer drugs); (Black diamond): cells cultured with anti-cancer drugs (CDDP + 5-FU). The arrows indicate 4, I5, 39 PDL in LoVo cells and 7, 27, 58 PDL in DLD-I cells, respectively.
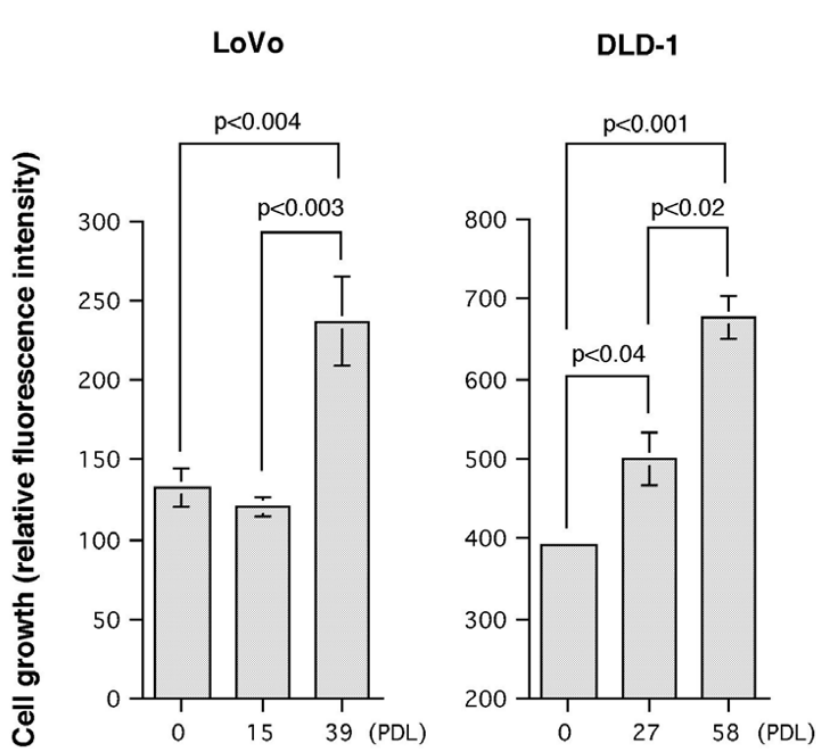

Figure 2

Cell proliferative activity of LoVo and DLD-I cells cultured with anti-cancer drugs. Cell growth activity at each passaged stage of the cells was measured by Alamar blue assay and expressed as relative fluorescence intensity. Each column and bar represents mean $\pm S D$ of triplicated experiments. $p$ values are calculated by the Student's $t$-test.

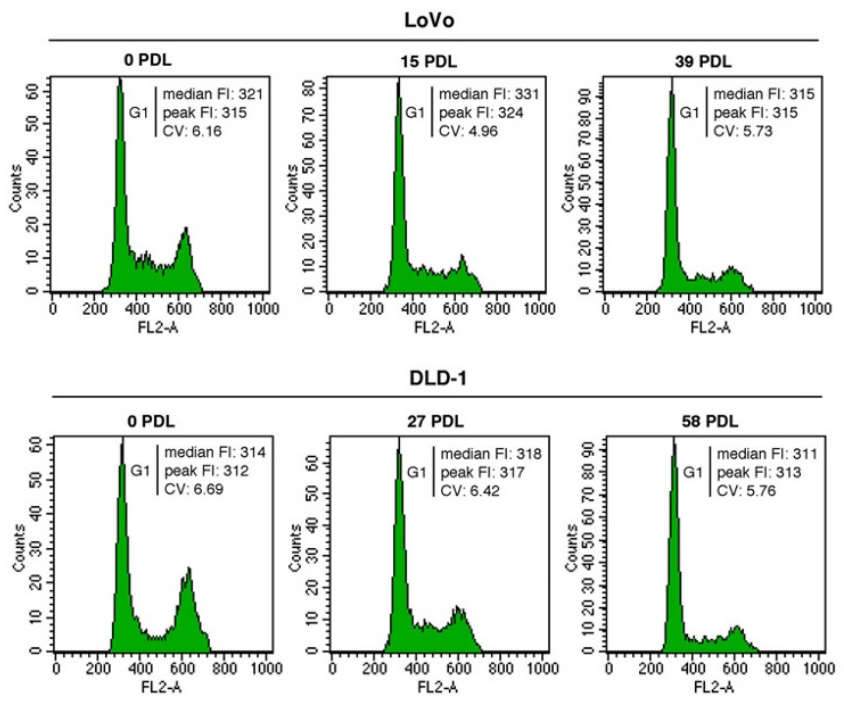

Figure 3

Flow cytometric analysis of the DNA histogram of the carcinoma cells cultured with anti-cancer drugs. DNA content (PI fluorescence intensity: FL-2 area) was expressed as a linear scale. Median fluorescence intensity (FI), peak FI and coefficient of variation (CV) are indicated on each panel. The variation of the peak FI among each PDL was less than $3 \%$ in LoVo cells and less than $2 \%$ in DLD-I cells, which suggests that no remarkable change in the chromosomal components occurs in either cells after the passage. 
A proliferative activity of the passaged cancer cells in the presence of anti-cancer drugs was measured by an Alamar blue assay (Fig. 2). In the first 15 PDL, proliferative activity of LoVo cells did not show any remarkable change compared to o PDL control cells. However, LoVo cells cultured for 39 PDL with anti-cancer drugs did show a remarkable increase in the proliferative activity ( $\mathrm{p}<0.004$ compared to o PDL, and $\mathrm{p}<0.003$ compared to 15 PDL). The proliferative activity of DLD-1 cells gradually increased as the PDL increased. There were significant differences between the growth capacity of o PDL and 27 PDL ( $\mathrm{p}<0.04)$, o PDL and 58 PDL ( $<<0.001)$, and 27 PDL and 58 PDL $(\mathrm{p}<0.02)$, respectively.

\section{Effect of long-term cultivation with anti-cancer drugs on the clonality of the passaged cancer cells}

To investigate the chromosomal stability of these passaged cancer cells, a DNA histogram analysis was performed by using a flow cytometer (Fig. 3). Although special attention should be paid to the improvement of DNA histograms quality, flow cytometry has been suggested to be a reliable method for measuring the tumor DNA content of the tumor cells [20]. As far as observing the DNA histogram pattern of both LoVo and DLD-1 cells at each PDL, neither an obvious appearance in the polyploid nor any shift in the median/peak fluorescence intensity (FI) was recognized, thus suggesting that major chromosomal changes such as deletion and duplication did not occur after long time cultivation of the cells with anti-cancer drugs.

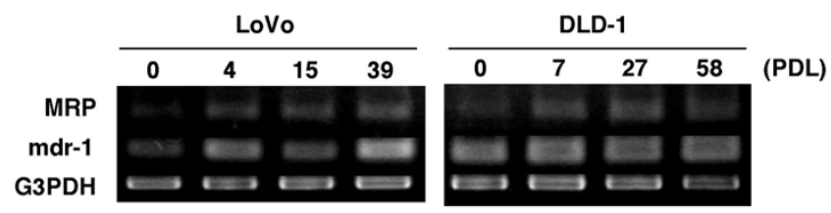

\section{Figure 4}

Effect of the long-term cultivation with anti-cancer drugs on the expression of drug resistance genes. An RT-PCR analysis of the MRP and mdr-I genes was performed by using the cells at each PDL. The G3PDH gene was used as an internal control.

\section{Effect of long-term cultivation with anti-cancer drugs on mdr-I and MRP gene expression}

The effect of passaging in the presence of anti-cancer drugs on the expression level of mdr-1 and MRP genes was evaluated by an RT-PCR analysis (Fig. 4). In both cell lines, the expression level of mdr-1 and MRP genes was upregulated after both survival and regrowth in the anti-cancer drugs. After processing the image by NIH software, the relative expression level of MRP and mdr-1 revealed 1.5-fold and 2.3-fold in LoVo cells at 39 PDL,

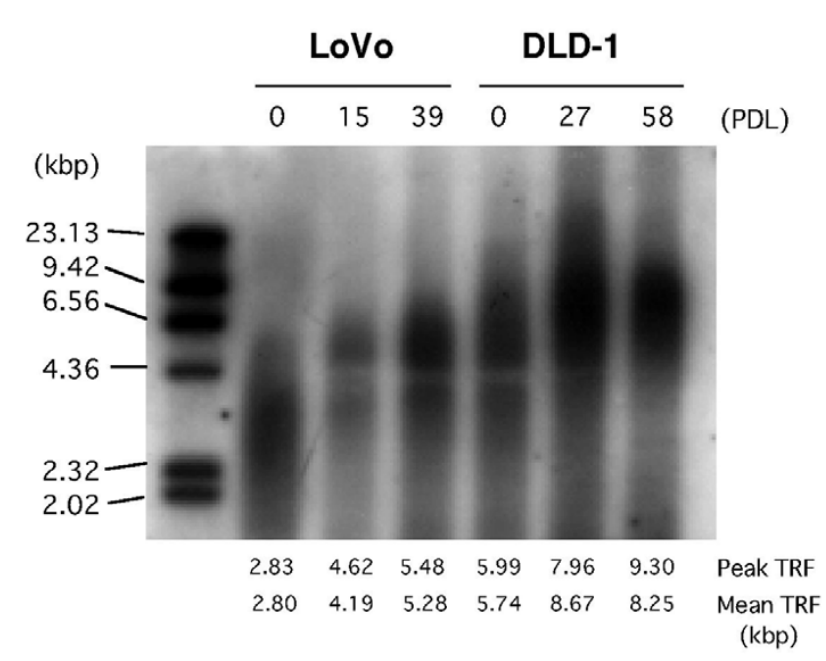

Figure 5

The effect of cultivation with anti-cancer drugs on the telomere length. The telomere length was measured by a TRF Southern blot analysis as described in the Materials and Methods. Peak and mean telomere restriction fragment (TRF) length was calculated by using an NIH image software.

and 1.3-fold and 1.4-fold in DLD-1 cells at 58 PDL, respectively. We confirmed that a simple passage of these cells in a normal culture medium without any anti-cancer drugs has no effect on the expression of mdr-1 and MRP (data not shown).

\section{Effect of long-term cultivation with anti-cancer drugs on the telomere length}

To investigate the effect of long-term culture with anticancer drugs on the stability of chromosomes, the telomere length of the genomic DNA of cultured cells was measured by a TRF Southern blot analysis (Fig. 5). In both cell lines, a remarkable elongation of the telomere length was observed as the PDL increased. The Peak TRF values of LoVo cells at 0,15 and 39 PDL were 2.83, 4.62 and $5.48 \mathrm{kbp}$, respectively. The mean TRF values of LoVo cells also revealed a gradual elongation as the PDL increased (2.80, 4.19 and $5.28 \mathrm{kbp}$, respectively). In DLD1 cells the peak TRF length at 0,27 and 58 PDL revealed 5.99, 7.96 and $9.30 \mathrm{kbp}$, and mean TRF values were 5.74, 8.67 and $8.25 \mathrm{kbp}$, respectively. Although the peak TRF showed a continuous elongation as the PDL increased, the mean TRF at 27 and 58 PDL were almost the same values. Accordingly, telomere elongation may reach a plateau in the case of DLD-1 cells.

\section{Effect of long-term cultivation with anti-cancer drugs on the telomerase activity}

To investigate the effect of long-term culture with anticancer drugs on the telomerase activity, a modifiedTRAP assay was performed (Fig. 6). Compared with the 


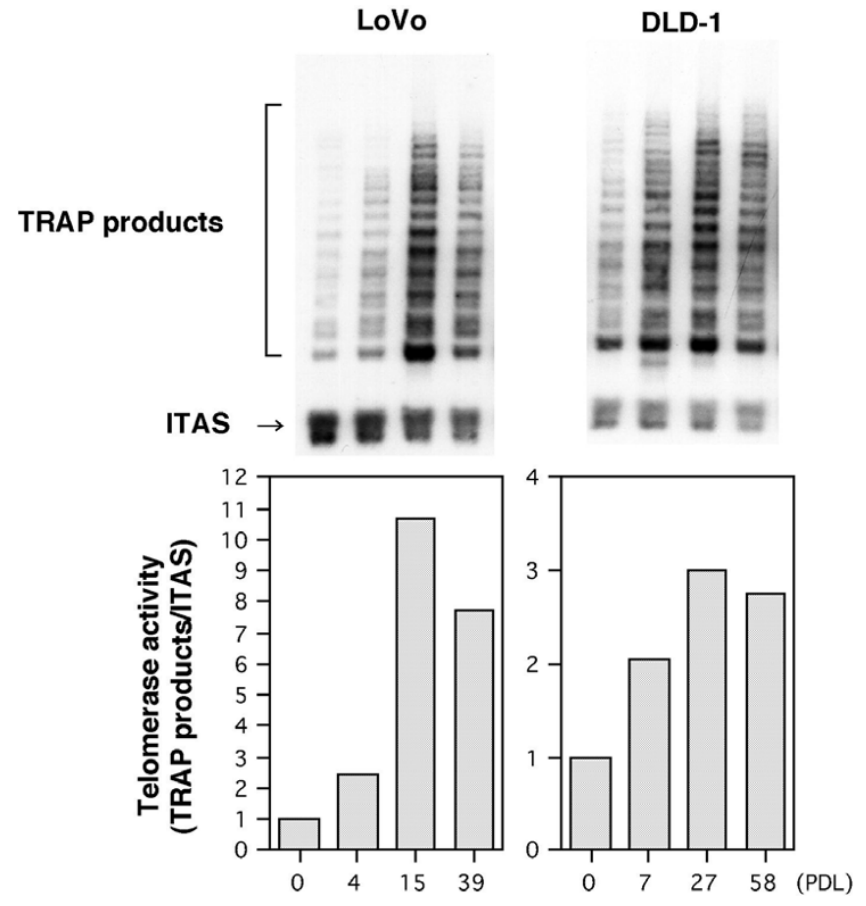

Figure 6

The effect of the long-term culture with anti-cancer drugs on the telomerase activity. The telomerase activity was observed by a modified-TRAP assay. Top: A ladder pattern after acrylamide gel electrophoresis. Bottom: the band intensity was measured using an $\mathrm{NIH}$-Image software package and telomerase activity (TA: band intensity of the TRAP products/band intensity of the ITAS) was also calculated. Thereafter, the TA was converted to the relative value (TA at 0 PDL $=$ I.0). All experiments were repeated at least three times and representative results are shown in this figure.

o PDL control cells, telomerase activity was upregulated after acquiring of resistance against anti-cancer drugs in both cell lines. In LoVo cells, the telomerase activity reached a maximun level at 15 PDL (10.7-fold), and then slightly decreased at 39 PDL but the activity still maintained at a high level (7.8-fold). The upregulation of the telomerase activity in DLD-1 cells was also observed after cultivation with anti-cancer drugs though the magnitude of the increase was smaller than that in the LoVo cells. The telomerase activity of DLD-1 cells at 7, 27 and 58 PDL was 2.0-, 3.0- and 2.8-fold, respectively and such activities were all quite similar, in contrast to LoVo cells.

\section{Effect of long-term cultivation with anti-cancer drugs on hTERT, hTR and TEP-I expression}

To analyze the telomerase activation on the gene level, the mRNA expression of three major gene components of the telomerase, hTERT, hTR and TEP-1, in the passages cells was observed (Fig. 7). The mRNA expression of hTERT and hTR was upregulated after acquiring resistance against anti-cancer drugs and the time course was

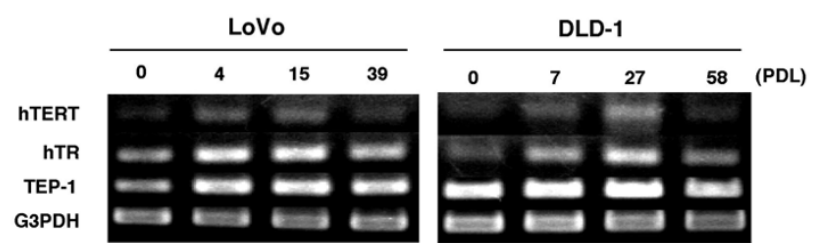

Figure 7

Effect of long-term culture with anti-cancer drugs on the mRNA expression of the three major gene components of telomerase, hTERT, hTR and TEP-I. An RT-PCR analysis of the hTERT, hTR and TEP-I genes was performed by using the cells at each PDL. The G3PDH gene was used as an internal control.

similar to that of the telomerase activity. Both hTERT mRNA and hTR mRNA reached a maximum level at 15 PDL in LoVo cells and at 27 PDL in DLD-1 cells, respectively. Although an upregulation of TEP-1 mRNA was also observed, the increase was not significant compared to that of hTERT and hTR.

\section{Discussion}

In this paper we investigated the role of the telomere length and telomerase activity during the acquisition of multidrug resistance in two colorectal carcinoma cell lines, LoVo cells and DLD-1 cells. When the cells were cultured with anti-cancer drugs, CDDP and 5-FU, cell growth was strongly suppressed during the first several PDL. Thereafter, the growth speed gradually increased and reached almost the same level as the control cells at 98 days (39 PDL) in LoVo cells and 85 days (58 PDL) in DLD-1 cells (Fig. 1). As the carcinoma cells acquired drug resistance, the cell growth accelerated significantly (Fig. 2). In this situation, the telomere length in both cell lines elongated considerably as the PDL increased (Fig. 5). During the process of telomere elongation, the telomerase activity was strongly upregulated, and then slightly decreased thereafter (Fig. 6). Since we did not perform any experiments regarding the single use of each agent, no conclusions based on the single use of each agent can be made. However, our present study is considered to represent the synergistic effect of these two drugs. It is commonly believed that activation of telomerase in colon cancer occurs during the process of extensive telomere shortening and oncogenesis. In addition, the telomeraseinduced stabilization of telomeres may be essential for the continued proliferation of malignant clones [21]. In our study, telomerase was remarkably upregulated in the cells that acquired drug resistance and active cell proliferative potential. An elongation of the telomeres in both LoVo and DLD-1 cells may be supported by the high telomerase activity. 
Generally speaking, however, only a slight correlation exists between the telomerase activity and telomere length in malignant tumor cells, and the levels of the telomerase components or telomerase activity are not predictive of the telomere length. Our finding that the telomere length was continuously elongated in both cell lines after incubation with anti-cancer drugs cannot be fully explained by increased telomerase activity because the increased telomerase activity reaches its peak at 15 PDL in LoVo cells and 27 PDL in DLD-1 cells, respectively. Thereafter, the level of telomerase activity decreased. The same tendency was also observed with levels of hTERT hTR and TEP-1. One probable interpretation for the telomere data is that anti-cancer drugs killed cells with short telomeres, thus resulting in the selective survival of cells with longer telomeres. Another explanation could be due to the involvement of an alternative lengthening of the telomeres (ALT) mechanism [22,23], which may play some role in the phase of low telomerase activity, although the precise mechanism is still unclear. These conclusions may differ from those in which there is active telomere elongation via an upregulation of the telomerase activity. However, it is also possible that the cells which possess a high telomerase activity and longer telomere were selected in the process of acquisition of multidrug resistance. Savre-Train et al. reported that clonal heterogeneity in telomerase activity and telomere length was observed in tumor-derived cell lines [24]. In their study, critically short telomeres in tumor-derived cell lines may upregulate the telomerase activity through an increase in the expression of the catalytic submit of telomerase. Although clones with a low telomerase activity shorten their telomeres over time, their subclones all have high levels of telomerase activity with no telomere shortening. In addition, there may also be fluctuation of activity levels in individual cells. Moreover, Kiyozuka et al. reported that the ovarian cancer cells with longer TRF and higher steady-state hTR expression showed significantly less sensitivity to CDDP [9]. These results support the hypothesis that the telomerase activity was upregulated and carcinoma cells possessing longer telomere may be selected during long-term cultivation with anticancer drugs. Actually in our study an increased expression of telomerase genes especially in hTERT, a catalytic component of the telomerase, was observed in the step of acquiring a growth advantage (Fig. 7).

The telomere length of HeLa cells treated with CDDP has been shown to become shortened after 24 to $72 \mathrm{hr}$ [25]. In addition, Burger et al. demonstrated that CDDP reduced telomerase activity of human testicular tumor cells in a specific and concentration-dependent manner within $4 \mathrm{hr}$ after treatment [26]. However, there have been no reports showing the change in the telomerase activity and telomere length of long-term cultured cancer cells in the presence of anti-cancer drugs. This is the first report describing the relationship between drug resistance and the elongation of telomeres. Regarding the relationship between drug resistance and telomerase activity, there is still no clear explanation. Terashima et al. reported the importance of a telomerase assay as a possible predictor of the response to anti-cancer chemotherapy by using several human gastric and breast cancer cells [26]. In their experiments, the telomerase activity correlated significantly with the number of viable cells, and after drug exposure the activity decreased rapidly in a dose dependent fashion. We observed a very low level of telomerase activity during the first several PDL in both LoVo and DLD-1 cell lines (data not shown; we confirmed this result by ELISA-based TRAP assay because we could not obtain a sufficient number of cells for the analysis due to the very slow proliferation speed around these PDL), and this also closely correlated with their results. However, in our study, as the PDL progressed, the cells regained their growth activity and this was also associated with a high level of telomerase activity. Ishikawa et al. reported similar results using MCF-7 breast carcinoma cells [27]. In the control cells, the telomerase activity decreased significantly due to the anti-cancer drug treatments; whereas in adriamycin-resistant cells, adriamycin significantly increased the enzyme activity while other drugs reduced enzyme activity. They thus concluded that an unusual reaction of telomerase activity might explain, at least in part, one of the mechanisms of the malignant biological behavior related with the drug resistance to adriamycin. During the process of acquiring drug resistance two quite different phases seem to exist regarding the telomerase activity, the former is a suppressive phase and the latter is a phase of upregulation. Therefore, telomere elongation may be the result of upregulated telomerase activity in the drug resistant cells. In our experiments, no obvious chromosomal changes (i.e. change in the DNA content) were not detected after long-term cultivation with anti-cancer drugs as far as could be observed on the DNA histogram level (Fig. 3). Since we did not perform a precise chromosome analysis, we can not completely rule out the possibility that telomere elongation is due to the appearance of an abnormal clone and the subsequent selection of this clone. However, the upregulation of the telomerase activity and the subsequent elongation of the telomeres may contribute to the drug resistance of colorectal carcinoma cells.

\section{Conclusions}

Taken together we conclude that the selection of the tumor cells that possess a strong resistance to anti-cancer drugs may occur in the process of long-term cultivation with anti-cancer drugs. It is also suggested that cancer cells with long telomeres and a high proliferative activity 
help such cells between survive under the anti-cancer drugs, presumably due to increased chromosome stability and strong expression of mdr-1 and MRP genes.

\section{List of abbreviations used}

PDL: population doubling level

mdr-1 gene: multidrug resistance gene

MRP: multidrug resistance-associated protein

CDDP: cis-dianuninedichloroplatinuni

5-FU: 5-fluorouracil

TRF: telomere restriction fragment

DIG: digoxigenin

TRAP: telomeric repeat amplification protocol

RT-PCR: reverse transcriptase polymerase chain reaction

\section{Declaration of competing interests}

The authors give no competing interests.

\section{References}

I. Goldstein LJ, Galski H, Fojo A, Willingham M, Lai SL, Gazdar A, Pirker R, Green A, Crist W, Brodeur GM: Expression of a multidrug resistance gene in human cancers J Natl Cancer Inst I989, 8 I: I I 6124

2. Roninson IB: Molecular mechanism of multidrug resistance in tumor cells Clin Physiol Biochem 1987, 5:|40-15 I

3. Cole SP, Bhardwaj G, Gerlach JH, Mackie JE, Grant CE, Almquist KC, Stewart AJ, Kurz EU, Duncan AM, Deeley RG: Overexpression of a transporter gene in a multidrug-resistant human lung cancer cell line Science 1992, 258:1650- | 654

4. Eijdems EW, De Haas M, Coco-Martin JM, Ottenheim CP, Zaman GJ, Dauwerse HG, Breuning MH, Twentyman PR, Borst P, Baas F: Mechanisms of MRP over-expression in four human lung-cancer cell lines and analysis of the MRP amplicon Int J Cancer 1995, 60:676-684

5. Schoenlein PV, Shen DW, Barrett JT, Pastan I, Gottesman MM: Double minute chromosomes carrying the human multidrug resistance $I$ and 2 genes are generated from the dimerization of submicroscopic circular DNAs in colchicine-selected KB carcinoma cells Mol Biol Cell I992, 3:507-520

6. Von Hoff DD, Waddelow T, Forseth B, Davidson K, Scott J, Wahl G: Hydroxyurea accelerates loss of extrachromosomally amplified genes from tumor cells Cancer Res 1991, 5 I:6273-6279

7. Ishikawa F: Telomere crisis, the driving force in cancer cell evolution Biochem Biophys Res Commun 1997, 230:1-6

8. Urquidi V, Tarin D, Goodison S: Role of telomerase in cell senescence and oncogenesis Annu Rev Med 2000, 5 I:65-79

9. Kiyozuka Y, Yamamoto D, Yang J, Uemura Y, Senzaki H, Adachi S, Tsubura A: Correlation of chemosensitivity to anticancer drugs and telomere length, telomerase activity and telomerase RNA expression in human ovarian cancer cells Anticancer Res 2000, 20:203-212

10. Oulton R, Harrington L: Telomeres, telomerase, and cancer: life on the edge of genomic stability Curr Opin Oncol 2000, I 2:7481

II. Hahn WC, Stewart SA, Brooks MW, York SG, Baton E, Kurachi A, Beijersbergen RL, Knoll JH, Meyerson M, Weinberg RA: Inhibition of telomerase limits the growth of human cancer cells Nat Med 1999, 5: I164-I170

12. Dong Y, Wen P, Manome Y, Parr M, Hirshowitz A, Chen L, Hirschowitz EA, Crystal R, Weichselbaum $R$, Kufe DW, et al: In vivo replication-deficient adenovirus vector-mediated transduction of the cytosine deaminase gene sensitizes glioma cells to 5 fluorocytosine Hum Gene Ther 1996, 7:713-720

13. Husain A, Yan XJ, Resales N, Aghajanian C, Schwartz GK, Spriggs DR: UCN-O I in ovary cancer cells: effective as a single agent and in combination with cis-diamminedichloroplatinum (II) independent of p53 status Clin Cancer Res 1997, 3:2089-2097

14. Counter CM, Avilion AA, LeFeuvre CE, Stewart NG, Greider CW Harley $C B$, Bacchetti S: Telomere shortening associated with chromosome instability is arrested in immortal cells which express telomerase activity EMBO J 1992, I I:1921-1929

15. Engelhardt M, Ozkaynak MF, Drullinsky P, Sandoval C, Tugal O, Jayabose $S$, Moore MA: Telomerase activity and telomere length in pediatric patients with malignancies undergoing chemotherapy Leukemia 1998, I 2:13-24

16. Okusa Y, Shinomiya N, Ichikura T, Mochizuki H: Correlation between telomerase activity and DNA ploidy in gastric cancer Oncology 1998, 55:258-264

17. Kim NW, Piatyszek MA, Prowse KR, Harley CB, West MD, Ho PL, Coviello GM, Wright WE, Weinrich SL, Shay JW: Specific association of human telomerase activity with immortal cells and cancer Science 1994, 266:201 I-2015

18. Abe Y, Nakamura M, Ota E, Ozeki Y, Tamai S, Inoue H, Ueyama Y, Ogata T, Tamaoki N: Expression of the multidrug resistance gene (MDRI) in non-small cell lung cancer Jpn J Cancer Res |994, 85:536-54|

19. Narasaki F, Matsuo I, Ikuno N, Fukuda M, Soda H, Oka M: Multidrug resistance-associated protein (MRP) gene expression in human lung cancer Anticancer Res 1996, 16:2079-2082

20. Rapi S, Caldini A, Fanelli A, Berti P, Lisi E, Anichini E, Caligiani R, Sbernini F, Taddei G, Amorosi A, et al: Flow cytometric measurement of DNA content in human solid tumors: a comparison with cytogenetics Cytometry 1996, 26:192-197

21. Engelhardt M, Drullinsky P, Guillem J, Moore MA: Telomerase and telomere length in the development and progression of premalignant lesions to colorectal cancer Clin Cancer Res 1997, 3:1931-1941

22. Bryan TM, Reddel RR: Telomere dynamics and telomerase activity in in vitro immortalised human cells Eur J Cancer 1997, 33:767-773

23. Aragona M, Maisano R, Panetta S, Giudice A, Morelli M, La Torre I, La Torre F: Telomere length maintenance in aging and carcinogenesis Int J Oncol 2000, I 7:98|-989

24. Savre-Train I, Gollahon LS, Holt SE: Clonal heterogeneity in telomerase activity and telomere length in tumor-derived cell lines Proc Soc Exp Biol Med 2000, 223:379-388

25. Ishibashi T, Lippard SJ: Telomere loss in cells treated with cisplatin Proc Natl Acad Sci USA 1998, 95:42 19-4223

26. Terashima M, Takiyama I, Uesugi N, Sasaki N, Takagane A, Hayakawa Y, Abe K, Araya M, Nishizuka S, Shimooki O, et al: Telomerase assay as a possible predictor of the response to anticancer chemotherapy Anticancer Res 2000, 20:293-297

27. Ishikawa T, Kamiyama M, Hisatomi H, Ichikawa $Y$, Momiyama N, Hamaguchi Y, Hasegawa S, Narita T, Shimada H: Telomerase enzyme activity and RNA expression in adriamycin-resistant human breast carcinoma MCF-7 cells Cancer Lett 1999, |41:187-194

\section{Pre-publication history}

The pre-publication history for this paper can be accessed here:

http://www.biomedcentral.com/content/backmatter/ 1471-2407-1-10-b1.pdf 